\title{
Attention Detection System Based on the Variability of Heart Rate
}

\author{
Ubaldo Enrique Rodríguez de Avila1 (), Isaac Campos Braga ${ }^{2}$ (D), \\ Fabíola Rodrigues de França Campos ${ }^{3}\left[\right.$, Adriano Chiombacanga Nafital ${ }^{4}$ \\ ${ }^{1}$ Department of Psychology of the Universidad del Magdalena, Santa Marta, Colombia \\ ${ }^{2}$ Biomedicine Graduation of Universidade Federal do Rio Grande do Norte, Natal, Brasil \\ ${ }^{3}$ Department of Physiotherapy of the Universidade Federal do Rio Grande do Norte, Natal, Brasil \\ ${ }^{4}$ Department of Biology of the Universidade Pungi, Chimoio, Mozambique \\ Email: rodriguez.ubaldo@gmail.com, isaacc@neuro.ufrn.br, fabiolafcampos@gmail.com, a.chiomba@yahoo.com.br
}

How to cite this paper: de Avila, U.E.R., Braga, I.C., de França Campos, F.R. and Nafital, A.C. (2019) Attention Detection System Based on the Variability of Heart Rate. Journal of Sensor Technology, 9, 54-70. https://doi.org/10.4236/jst.2019.94006

Received: October 23, 2019

Accepted: November 23, 2019

Published: November 26, 2019

Copyright $\odot 2019$ by author(s) and Scientific Research Publishing Inc. This work is licensed under the Creative Commons Attribution International License (CC BY 4.0).

http://creativecommons.org/licenses/by/4.0/

\begin{abstract}
Attention is a cognitive and psychobiological variable that lacks objective measures in natural contexts of formal learning. However, it can be objectively measured from the heart autonomic activity. In the present study, the validity and reliability of a system for recording heart rate variability are demonstrated. Twelve prototypes were created and paired with standard electrocardiogram. Long segments with cardiac pulse recordings were used within ten minutes. A highly significant correlation index $(\mathrm{p}<0.01)$ and a significantly high Cronbach's alpha were obtained. In the variance analysis, all data analyzed presented a value of $p<0.05$. It is concluded that there is no significant variation between paired systems; therefore, the attention detection system based on heart rate variability is valid and reliable.
\end{abstract}

\section{Keywords}

Arduino, RR Interval, Heart Rate Variability, Attention

\section{Introduction}

The Porges Polyvagal Perspective relates the autonomic function with the behavior and defines the Autonomic Nervous System (ANS) as "system" [1] [2] [3] and in that line, Thayer, Hansen, Saus-Rose and Johnsen [4] proposed the Neurovisceral Integration Model, which exposes the existence of a network of neural structures related to the regulation of physiological processes, cognitive processes and emotional processes, which they called Central Autonomic Net- 
work (CAN), which is part of an internal regulation system that innervates the heart through the pathways of the Sympathetic Nervous System (SNS) and Parasympathetic Nervous System (PNS) [5]. In summary, the regulatory activity of CAN is related to Heart Rate Variability (HRV), which is the result of interactions between the SNS and the PNS [6], with an impact on cognitive and emotional processes [5] [7].

Thus, the activation of the SNS produces an increase in the Heart Rate (HR) by slow impulses of low frequency, due to physical and mental stress. In contrast, PNS lowers HR by high-frequency vagal electrical impulses and manages changes in the HR due to signals from arterial baroreceptors and the respiratory system [5]. This is why the HRV study allows us to observe the fluctuating predominance of the SNS and PNS, which makes it possible to measure the Attention objectively. In this way, the association of the communication pathways between the heart and the brain is responsible for the generation of Heart Rate Variability (HRV).

Therefore, the fundamental premise of the present study is deduced, which consists in the idea that the care has a physiological substrate, regulated by the activity of the ANS (SNS and PNS) to the extent that the SNS has as a function the acceleration of the responses of the organism and the preparation for action (stress) and therefore increases the levels of cognitive attention, and thus, the HR increases [8] [9] [10]. On the other hand, the predominance of PNS causes a resting body state in the body, reducing the level of stress [6]. Therefore, attention, in addition to being a central and fundamental aspect of cognition [11], is related to the models of neuronal integration and learning regulated by attention [12] [13]. There is already evidence that the ANS plays a fundamental role in implicit learning [14], in cognition, emotion and mainly in attention [15].

Also, the electrophysiology in the study of the HRV, has been experiencing a growing and rapid expansion with increasing complexity and the number of techniques performed [16] that together with the scientific evidence set forth above, it is found that HRV is emerging as a simple non-invasive measure, or quantitative marker, of autonomic activity [16], which can also be used as an objective measure for the study of autonomic processes related to cognitive processes [17] [18] [19] [20] (Luque-Casado, Perales, Cárdenas \& Sanabria, 2016) (Figure 1).

Flexible electronic devices are emerging as powerful tools to measure biological signals, such as HR or a person's blood pressure [21]. The basic research based on objective psychobiological records provides foundations for future flexible technologies [22], but these advances can only be transformed into concrete products if technological innovation advances from the laboratory, even more so when they are systems designed to be applied in life research and pedagogical or formative activity.

In this perspective, various techniques have been developed for the calculation of $\mathrm{HR}$ using the $\mathrm{R}$ wave. Some of them employ demanding procedures such as 


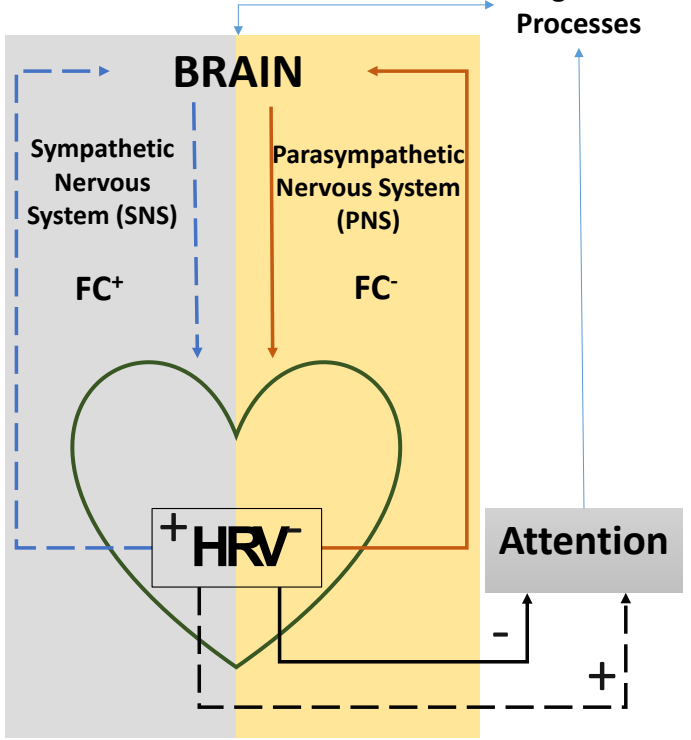

Figure 1. Simplified theoretical model scheme. Source: The authors.

expensive programmable devices, with adaptive threshold calculation, filter banks, transformations and mathematical operations, among other alternatives of measurement [23] [24]. They also use programmable digital devices, advanced machines type RISC (Reduced Instruction Set Computer), which is a 32-bit RISC architecture developed by ARM Holding, becoming a dominant alternative in the mobile electronics market [25]. We can also mention the Olimexino STM32, which is an open source development card, Arduino type, with STM32F103RBT6 microcontroller, with DC-DC power supply from 9 to $30 \mathrm{~V}$, low consumption voltage regulators and with Micro SD-card system for data storage [25]. There is also a history of reliable use of systems such as the Shiel EKG-EMG, Arduino DUE, or the Arduino Ethernet Shield, etc. [25].

In a study developed by Weippert et al. [26] three mobile devices were compared to measure the RR intervals and HR. The devices were the Polar S810i, Suunto t6 and an ambulatory EKG system. The participants were subjected to simultaneous recordings of the RR interval with the three instruments during rest in the supine and sitting position, moderate dynamics and moderate to vigorous static exercise of the upper and lower limb. For each subject, 17 series of $\mathrm{RR}$ intervals with 3-minute recordings were extracted and then analyzed in the frequency domain using the Fast Fourier Transform (FFT). To compare the reliability of the data (measurement matching criteria), the researchers determined the intraclass correlation coefficients (ICC) and the Bland-Altman agreement limits method (LoA). The results showed agreement between all the devices.

Also, Urbano [25] carried out a study whose objective was to design an algorithm for the quantification of the average heart rate, from the detection of the $\mathrm{R}$ wave, oriented to its implementation in programmable digital devices of the 
ARM type; where one of the specific objectives was to identify the possibility of implementing an integration strategy with data storage devices in removable memory and communication with the personal computer, in order to facilitate the exposure of the data quickly.

As far as we know, there are no technological development studies for the registration of the HRV with a simple device, easy to program, agile to assemble and robust enough to be used in scientific research and in pedagogical activity, low cost and free use.

Therefore, the objective of this study was to design and validate an accessible, low-cost, flexible and easy-to-use tool for researchers and students, with the same performance of sophisticated controls and more complex tools, which can be used to the development of the investigation of records of the HRV, or to be connected to a central computer based on the online pedagogical activity.

\section{Method}

\subsection{Attention Detection System Based on the Variability of Heart Rate (ADS-VHR1)}

The study is design and validation of ADS-VHR1. The measurement of observation is the registered cardiac pulses. With twelve (12) systems paired with a Standard Electrocardiogram (EKG-P). The sample was defined a posteriori, that is: It was identified after the cardiac pulse records. The participating subjects were: Three volunteers, men, who enjoyed good health, and before or during the test, did not take any substance that altered their physiology.

The ADS-VHR1 is based on Arduino Technology. This technology is a platform for free hardware electronic prototypes and a single board, projected with a microcontroller, by integrated input and output gate and standard programming language [27] [28]. It is composed of an Arduino UNO microprocessor; a pulse sensor; an SD Card Module; a Protoboard; a Psh-button for event marking. The components of the System are basically five, in addition to the wiring and support. They described below:

1) Arduino: It is an open-source electronic prototype platform based on flexible hardware and software. The board's microcontroller is programmed using the Arduino Programming Language (based on Wiring) and the Arduino Development Environment (based on Processing). It can also be defined as a tiny computer that can be programmed to process inputs and outputs between the device and the external components that connect to it [28].

The ADS-VHR1 prototype was designed with software running on a common computer for later use, powered by a 9-volt battery (see code in Appendix). System components were purchased from authorized suppliers, and then assembled by hand. The reference hardware designs are available under an open-source license, so it is free to be adapted to the different needs of the user [27] [28].

2) Protoboard: It consists of a plate with a matrix of contacts that allows the construction of experimental circuits without welding, which makes it fast and 
safe to alter the position of a certain component, including its replacement.

3) Micro SD Memory Card Module: It is a device that uses the recorded information, in text format, on a standard micro SD card as storage. It allows to store the information during a variable registration time and then be processed in the computer.

4) Heart Rate Sensor. It is an amplified optical sensor that makes the reading of the heartbeat. The Arduino microcontroller processes it, by means of the code that converts the registered signal into numbers, which correspond to the distance in milliseconds of each heart pulse or RR interval, and then that data is sent through cables connected to the Protoboard, which in turn, it sends the information to the Micro SD Card Module and stored there, to be later downloaded to a conventional PC and the data processed.

5) 9 Volt Battery $(9 \mathrm{~V})$ : It is the power source or power supply of the ADS-VHR1, when it is not connected to the computer.

The ADS-VHR1 is programmed with free software that does not need to be online, is used in a portable way and the information is removable to be processed in a conventional computer, using other free software that also does not need to be connected to the web (Figure 2).

\subsection{Design of the ADS-VHR1}

Initially, three ADS-VHR1 prototypes were built, which were subjected to pre-pilot tests, which allowed to adjust the Arduino's processing code, Heart Rate sensors, the power supply system and the storage capacity. After this phase, the rest of the prototypes were assembled, which were also subjected to a previous Pilot to verify that the components were adequate and suitable for definitive use.

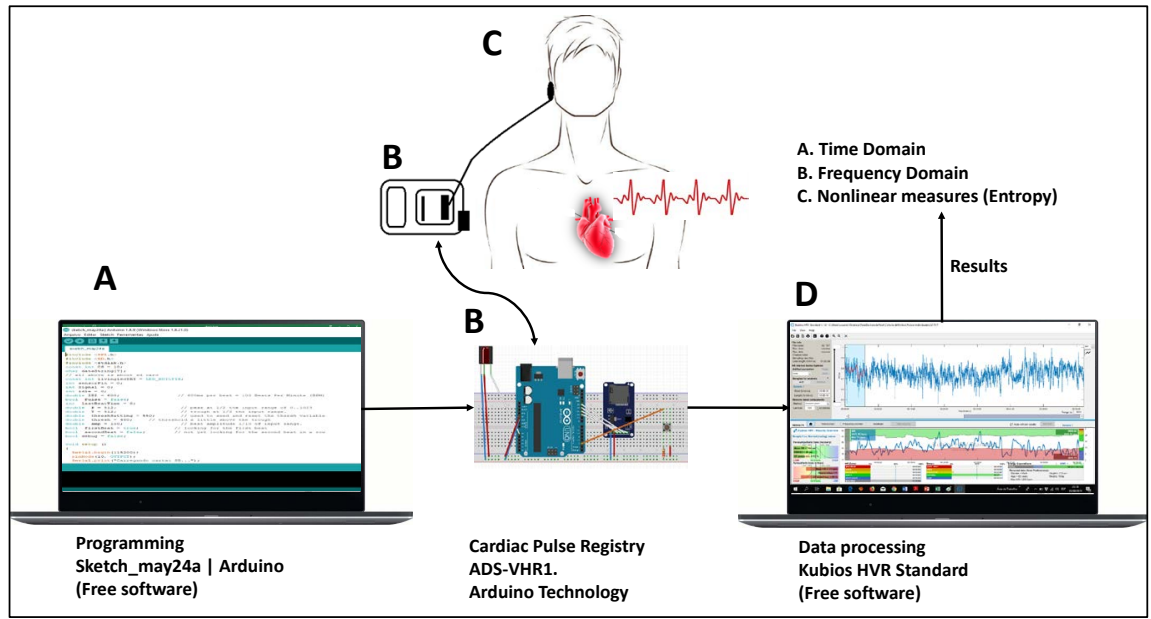

Figure 2. Schematic representation of the use of ADS-VHR1. A: Conventional computer with specialized software, free to use, with ADS-VHR1 programming algorithm. B: ADS-VHR1 assembled and programmed for recording cardiac activity. C: Subject with the ADS-VHR1 heart rate sensor in the ear. D: Processing of the registered data extracted from the ADS-VHR1, using specialized software for free use. Source: The authors. 
After verifying that the hardware and software components were adequate, the test for the final validation was carried out. Twelve (12) paired records were made (corresponding to one for each ADS-VHR1 system). The tests were done with subjects in a sitting position, at rest.

The EKG-P used was the LabChart, which is software supplied by PowerLab, which is part of a group of systems for research. LabChart software transforms the computer into a digital recorder and oscilloscope that records and displays EKG data in real time. The benefits it presents are easy acquisition, graphic presentation and powerful analysis functions. The values of the RR intervals recorded and processed were extracted from LabChart software; they were stored on the local PC using the interfaces and software supplied by the manufacturer. The records of the values of the RR intervals were then imported into an Excel 2007 version.

On the other hand, the cardiac pulse registers recorded by the ADS-VHR1, were stored in the SD memory card of this system, were exported for the Excel 2007 version on a local computer for later analysis.

In the validation analysis, the long segments of the recordings of the cardiac pulse values (RR intervals) in ten (10) minute time were used, also extracting for each system a random sample of the number of RR Intervals to be able to compare the system data objectively. Twelve (12) paired records were made, corresponding to twelve (12) ADS-VHR1 (Figure 3).

\subsection{Information Processing}

The data is described by descriptive statistics (central tendency, dispersion and

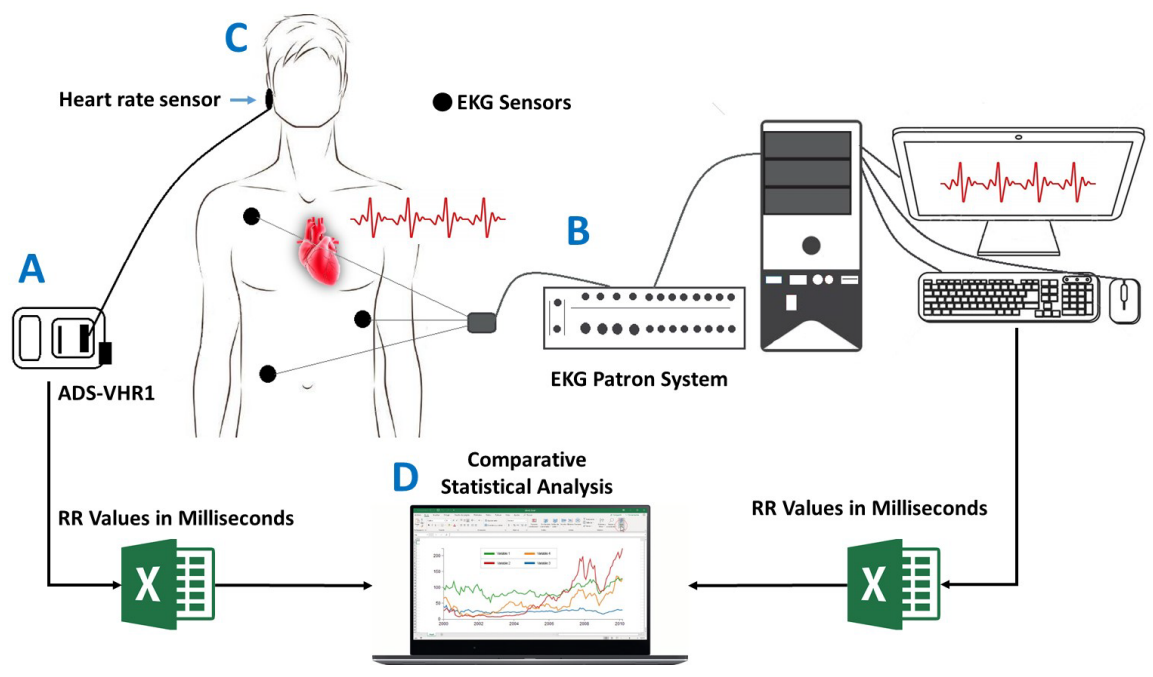

Figure 3. Validation of ADS-VHR1 by paired systems method. A: The ADS-VHR1 assembled and programmed. B: EKG-P system (Labchart). C: Experimental subject with the ADS-VHR1 heart rate sensor placed in the ear and electrocardiogram sensors, located in the thorax and abdomen. Simultaneously the cardiac activity is recorded in a time of 10 minutes. D: The cardiac pulse registers are extracted from each System and processed in a conventional computer by statistical tests. Source: The authors. 
distribution). Data were explored to verify Normality using the Kolmogorov-Smirnov tests. The validity of ADS-VHR1 was explored by calculating the correlation between paired systems, intra-class correlation (individual and average) and Cronbrach's Alpha. Then, in a confirmatory manner, a Variance Analysis (ANOVA) is performed between the paired systems. And it also shows graphically the correlation of the systems by means of scatter plots for each paired system.

The following computer packages were used:

- Sketch_may24a/Arduino1.8.9 (for Windows): Used for mounting the ADS-VHR1 code (Appendix).

- IBM Statistics SPSS 20. Computer statistical program widely used in the social, health and economic sciences.

- Microsoft Excel for Windows. Statistical support program and establishment of databases.

\section{Results}

Table 1 presents the descriptive statistics and the standard deviation of the data obtained from the paired EKG-P and ADS-VHR1 Systems.

The criteria to determine Normality were the following:

$\mathrm{p}$ Value $>0.05$, accept $\mathrm{Ho}=$ Data have normal distribution

$\mathrm{p}$ Value $<0.05$, accept $\mathrm{H} 1=$ Data does NOT have normal distribution

The data recorded by the standard EKG (EKG-P) and the ADS-VHR $1_{1-10}$ had a NO Normal distribution. While the data recorded for the EKG-P and ADS-VHR $1_{11-12}$ followed a Normal distribution (Table 1).

In the cross-correlation (bivariate), it was verified that there is a highly significant correlation index $(\mathrm{p}<0.01)$ (Table 2$)$. In addition, the correlation was plotted using a scatter plot to observe the correspondence between the systems, calculating the estimated vector distance-R2 (Figure 4).

As an exploratory analysis, cross-correlation (paired), intraclass correlation was calculated and Cronbach's Alpha ( $\alpha$ ) was verified; an $\alpha=0.61$ was found for ADS-VHR1-5, whose $\alpha$ is considered weak (Table 2), which means low reliability $(61 \%)$.

Subsequently, a confirmatory analysis was carried out, beyond the data offered by the Cronbach Alpha, by means of an Analysis of the Variance for all the data, resulting in the validity of all the systems, including the ADS-VHR1-5. The hypotheses were established as follows:

$\mathrm{Ho}=$ There is significant VARIANCE between the Paired Systems.

$\mathrm{H} 1=$ There is no significant VARIANCE between the Paired Systems.

If $\mathrm{P}$ Value $<\alpha$, Ho is rejected ( $\mathrm{H} 1$ is accepted).

If $\mathrm{P}$ Value $>\alpha, \mathrm{H} 1$ is rejected (Ho is accepted).

The value of $\alpha=0.05$ (5\% error and 95\% confidence) was determined.

In this way, all the analyzed data had a value of $\mathrm{p}<0.05$. It is concluded that there is no significant variance between the systems (see Table 2). 
These results suggest, on the one hand, a very good agreement between ADS-VHR1 and EKG-P. Therefore, it can be affirmed that there are no relevant biases for the measurements of the RR intervals by the ADS-VHR1.

However, referring to the reliability data offered by intraclass correlations and Cronbach's Alpha value, we notice a 38\% difference between extreme values of Cronbach's Alpha (see Table 2), which somehow indicates that the ADS-VHR1 has a certain variability that the researcher must take into account when using.
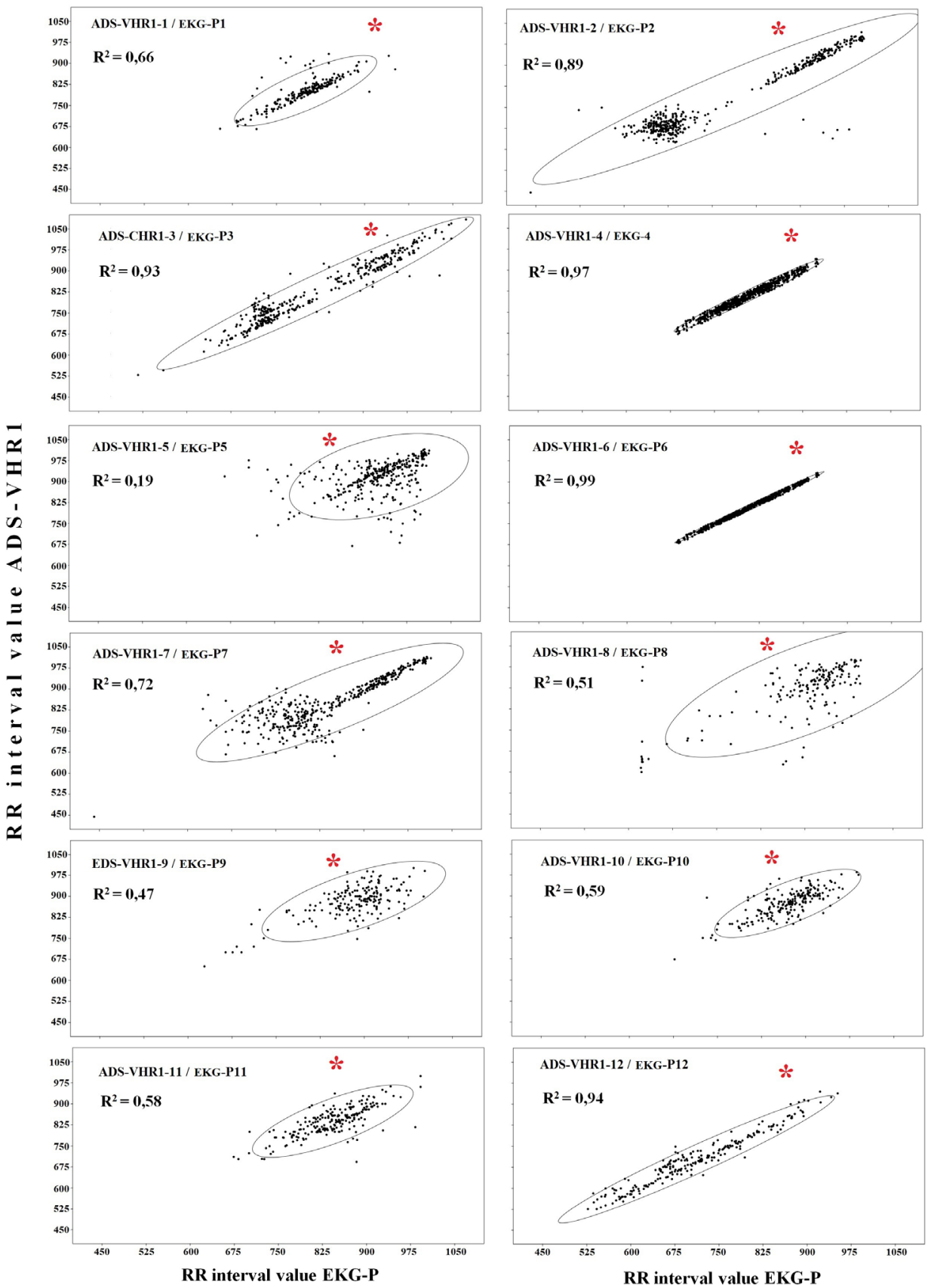

Figure 4. Correlation graph between paired systems. The ellipse shows the minimum correspondence of $95 \%$ in the distribution of the data. R2. It is the estimated vector distance between the paired systems. ${ }^{*} \mathrm{p}<0.01$ in the correlation (R) (Table 2, correlation data $\mathrm{R}$ ). 


\section{Conclusions}

The programmable digital device based on the Arduino platform, has sufficient reliability, as found in previous research [25], however it is necessary to take into account that this variability found between the various measures performed with the ADS-VHR1 and the EKG-P, it can be due to a possible instability in its components, for example in cardiac pulse sensors, in the storage system in micro SD cards or, mainly, in the feeding system by means of $9 \mathrm{v}$ batteries, since it is necessary to have noted that the EKG-P system works with electric current and therefore provides greater stability in its operation.

Table 1. Descriptive statistics and normality test for data from ADS-VHR1 and EKG-P.

\begin{tabular}{|c|c|c|c|c|c|c|}
\hline \multirow{2}{*}{ Systems } & \multicolumn{5}{|c|}{ Descriptions } & \multirow{2}{*}{$\begin{array}{c}\text { Normality Test } \\
\mathrm{p} \text { value }\end{array}$} \\
\hline & $\mathrm{N}$ & Minimum & Maximum & M & DS & \\
\hline EKG-P1 & 260 & 610 & 952 & 777.6 & 64.09 & * \\
\hline ADS-VHR1-1 & 260 & 605 & 937 & 775.5 & 73.61 & * \\
\hline EKG-P2 & 437 & 441 & 1008 & 774 & 133.78 & * \\
\hline ADS-VHR1-2 & 437 & 445 & 1018 & 778.8 & 124.22 & * \\
\hline EKG-P3 & 423 & 441 & 1075 & 812.5 & 111.96 & * \\
\hline ADS-VHR1-3 & 423 & 445 & 1106 & 816.6 & 110.48 & * \\
\hline EKG-P4 & 767 & 685 & 926 & 808.3 & 51.77 & * \\
\hline ADS-VHR1-4 & 767 & 672 & 940 & 810.3 & 52.86 & * \\
\hline EKG-P5 & 371 & 665 & 1013 & 927.5 & 61.88 & * \\
\hline ADS-VHR1-5 & 371 & 669 & 1015 & 917.4 & 62.51 & * \\
\hline EKG-P6 & 767 & 685 & 926 & 808.3 & 51.77 & * \\
\hline ADS-VHR1-6 & 767 & 680 & 932 & 809.3 & 52.14 & * \\
\hline EKG-P7 & 414 & 441 & 1014 & 841.4 & 93.86 & * \\
\hline ADS-VHR1-7 & 414 & 445 & 1015 & 852 & 86.03 & * \\
\hline EKG-P8 & 184 & 621 & 995 & 892 & 92.61 & * \\
\hline ADS-VHR1-8 & 184 & 600 & 1000 & 887.7 & 94.98 & * \\
\hline EKG-P9 & 186 & 628 & 1003 & 882.2 & 63.09 & * \\
\hline ADS-VHR1-9 & 186 & 650 & 1001 & 881.7 & 57.99 & * \\
\hline EKG-P10 & 207 & 677 & 990 & 869.6 & 50.31 & * \\
\hline ADS-VHR1-10 & 207 & 674 & 985 & 873.6 & 49.37 & * \\
\hline EKG-P11 & 213 & 674 & 992 & 842.6 & 55.36 & $0.20^{* *}$ \\
\hline ADS-VHR1-11 & 213 & 693 & 999 & 838.3 & 52.32 & $0.08^{* *}$ \\
\hline EKG-P12 & 229 & 527 & 952 & 711.7 & 95.18 & $0.92^{* *}$ \\
\hline ADS-VHR1-12 & 229 & 526 & 945 & 703.5 & 92.02 & $0.35^{\star *}$ \\
\hline
\end{tabular}

${ }^{*} \mathrm{p}<0.05=$ Non-Normal Distribution. ${ }^{*} \mathrm{p}>0.05=$ Normal Distribution. The normality test used was Kolmogorov-Smirnov. The $\mathrm{N}$ value represents the number of cardiac pulses, measured in the distance between two successive $\mathrm{R}$ waves, in a recording time of 10 minutes. 
Table 2. Correlation and analysis of the variance in paired systems data.

\begin{tabular}{|c|c|c|c|c|c|}
\hline \multirow{2}{*}{ Paired Systems } & \multirow{2}{*}{$\mathrm{R}$} & \multicolumn{2}{|c|}{ Intraclass Correlation } & \multirow{2}{*}{$\alpha$} & \multirow{2}{*}{ Variance } \\
\hline & & Individual & Average & & \\
\hline EKG-P1-ADS-VHR1-1 & $0.839\left(^{*}\right)$ & 0.813 & 0.897 & 0.90 & $\mathrm{f}=3.82(\mathrm{p}<0.05)$ \\
\hline EKG-P2-ADS-VHR1-2 & $0.799\left(^{*}\right)$ & 0.943 & 0.971 & 0.98 & $\mathrm{f}=32.36(\mathrm{p}<0.05)$ \\
\hline EKG-P3-ADS-VHR1-3 & $0.930\left(^{*}\right)$ & 0.965 & 0.982 & 0.98 & $\mathrm{f}=33.37(\mathrm{p}<0.05)$ \\
\hline EKG-P4-ADS-VHR1-4 & $0.986\left(^{*}\right)$ & 0.987 & 0.993 & 0.99 & $\mathrm{f}=161.5(\mathrm{p}<0.05)$ \\
\hline EKG-P5-ADS-VHR1-5 & $0.569\left(^{*}\right)$ & 0.434 & 0.605 & 0.61 & $\mathrm{f}=2.933(\mathrm{p}<0.05)$ \\
\hline EKG-P6-ADS-VHR1-6 & $0.996\left(^{*}\right)$ & 0.997 & 0.998 & 0.99 & $\mathrm{f}=616.8(\mathrm{p}<0.05)$ \\
\hline EKG-P7-ADS-VHR1-7 & $0.812\left(^{*}\right)$ & 0.834 & 0.909 & 0.91 & $\mathrm{f}=10.39(\mathrm{p}<0.05)$ \\
\hline EKG-P8-ADS-VHR1-8 & $0.604\left(^{*}\right)$ & 0.713 & 0.833 & 0.83 & $\mathrm{f}=2.74(\mathrm{p}<0.05)$ \\
\hline EKG-P9-ADS-VHR1-9 & $0.524\left(^{*}\right)$ & 0.686 & 0.814 & 0.81 & $\mathrm{f}=1.86(\mathrm{p}<0.05)$ \\
\hline EKG-P10-ADS-VHR1-10 & $0.729\left(^{*}\right)$ & 0.771 & 0.871 & 0.87 & $\mathrm{f}=3.63(\mathrm{p}<0.05)$ \\
\hline EKG-P11-ADS-VHR1-11 & $0.766\left({ }^{* *}\right)$ & 0.765 & 0.867 & 0.87 & $\mathrm{t}=2.92(\mathrm{p}<0.05)$ \\
\hline EKG-P12-ADS-VHR1-12 & $0.972\left(^{* *}\right)$ & 0.971 & 0.985 & 0.99 & $\mathrm{t}=28.41(\mathrm{p}<0.05)$ \\
\hline
\end{tabular}

* Spearman's correlation $(\mathrm{p}<0.01)$. ** Pearson correlation $(\mathrm{p}<0.01) . \boldsymbol{\alpha}=$ Cronbach's alpha. $\mathrm{f}=$ Fish er-Snedecor. $\mathrm{t}=\mathrm{T}$-Student statistic. It is concluded that there is no significant difference between the systems analyzed.

Thus, in regard to the sensors of the cardiac pulses, for example, we discover that it presents inconveniences in what seems to be the capture of the cardiac pulses in people with dark skin. In the same way, the storage card in the micro SD memory, presents conflicts and did not allow to tax the information when the SD-card memory exceeded the $8 \mathrm{G}$ storage capacity. Therefore, the ADS-VHR1 must be periodically reviewed to verify its components and change them when necessary; being this condition, at the same time, an advantage, since being low cost, allows the replacement of its parts in an easy and affordable way [27] [28] [29] [30].

Despite these limitations of ADS-VHR1, there was no systematic bias in its operation. On the other hand, the individual data recorded by each ADS-VHR1 paired with the EKG-P, suggest that the agreement between the devices may also depend on the different positions of the electrodes of the EKG-P and the heart rate sensors of the ADS-VHR1, and therefore, the effects on the time of detection of cardiac pulses in fractions of thousandths of seconds. However, all the differences in the records were within accepted limits to conclude their validity.

It was shown that Arduino technology, free and open base, is a powerful tool for research activity, at low cost and easily accessible to teachers and new researchers who do not have proficient knowledge in the area of programming.

\section{Disclaimer}

The views expressed in this paper are solely those of the authors and do not necessarily reflect the views of any company or organization. 


\section{Ethical Aspects}

This study was financed in part by the Coordenação de Aperfeiçoamento de Pessoal de Nível Superior-Brasil (CAPES)-Finance Code 001. Approved by the ethics committee of the UFRN (Parecer Consubstanciado do CEP No: $2,683,191)$. It is a product of the Doctoral Thesis carried out at the Universidade Federal do Rio Grande do Norte, Brasil, titled: ATENÇÃO SUSTENTADA NA SALA DE AULA: MODULAÇÃO DA PERSONALIDADE, EMOÇÃO E CRONOTIPO.

\section{Conflicts of Interest}

The authors declare no conflicts of interest regarding the publication of this paper.

\section{References}

[1] Porges, S.W. (1995) Orienting in a Defensive World: Mammalian Modifications of Our Evolutionary Heritage: A Polyvagal Theory. Psychophysiology, 32, 301-318. https://doi.org/10.1111/j.1469-8986.1995.tb01213.x

[2] Porges, S.W. (2001) The Polyvagal Theory: Phylogenetic Substrates of a Social Nervous System. International Journal of Psychophysiology, 42, 123-146. https://doi.org/10.1016/S0167-8760(01)00162-3

[3] Porges, S.W. (2007) The Polyvagal Perspective. Biological Psychology, 74, 116-143. https://doi.org/10.1016/j.biopsycho.2006.06.009

[4] Thayer, J.F., Hansen, A.L., Saus-Rose, E. and Johnsen, B.H. (2009) Heart Rate Variability, Prefrontal Neural Function, and Cognitive Performance: The Neurovisceral Integration Perspective on Self-Regulation, Adaptation, and Health. Behavioral Medicine, 37, 141-153. https://doi.org/10.1007/s12160-009-9101-z

[5] Fonfría, A., Poy, R., Segarra, P., López, R., Esteller, A., Ventura, C., Moltó, J., et al. (2011) Variabilidad de la tasa cardíaca (HRV) y regulación emocional. Fòrum de Recerca, 16, 903-913.

[6] Holzman, J. and Bridgett, D. (2017) Heart Rate Variability Indices as Bio-Markers of Top-Down Self-Regulatory Mechanisms: A Meta-Analytic Review. Neuroscience and Biobehavioral Reviews, 74, 233-255.

https://doi.org/10.1016/j.neubiorev.2016.12.032

[7] Capuana, L.J., Dwyan, J., Tays, W.J., Elmers, J.L., Witherspoon, R. and Segalowitz, S. (2014) Factors Influencing the Role of Cardiac Autonomic Regulation in the Service of Cognitive Control. Biological Psychology, 102, 88-97. https://doi.org/10.1016/j.biopsycho.2014.07.015

[8] Shaffer, F. and Venner, J. (2013) Heart Rate Variability Anatomy and Physiology. Biofeedback, 41, 13-25. https://doi.org/10.5298/1081-5937-41.1.05

[9] Shaffer, F., McCraty, R. and Zerr, C. (2014) A Healthy Heart Is Not a Metronome: An Integrative Review of the Heart's Anatomy and Heart Rate Variability. Frontiers in Psychology, 5, 1040. https://doi.org/10.3389/fpsyg.2014.01040

[10] Reyes Del Paso, G.A., Langewitz, W., Mulder, L.J.M., Van Roon, A. and Duschek, S. (2013) The Utility of Low Frequency Heart Rate Variability as an Index of Sympathetic Cardiac Tone: A Review with Emphasis on a Reanalysis of Previous Studies. Psychophysiology, 50, 477-487. https://doi.org/10.1111/psyp.12027 
[11] Yoo, K., Rosenberg, M., Hsu, W., Zhang, S., Li, C., Scheinost, D., Constable, T. and Chun, M. (2018) Connectome-Based Predictive Modeling of Attention: Comparing Different Functional Connectivity Features and Prediction Methods across Datasets. NeuroImage, 167, 11-22. https://doi.org/10.1016/j.neuroimage.2017.11.010

[12] Rohr, C., Arora, A., Cho, I., Katlariwala, P., Dimond, D., Dewey, D. and Bray, S. (2018) Functional Network Integration and Attention Skills in Young Children. Developmental Cognitive Neuroscience, 30, 200-211.

https://doi.org/10.1016/j.dcn.2018.03.007

[13] Onley, A., Risko, E., D’mello, S. and Graesser, A. (2015) Attention in Educational Contexts: The Role of the Learning Task in Guiding Attention. In: Fawcett, J., Risko, E. and Kingstone, A., Eds., The Handbook of Attention, MIT Press, London, 623-641.

[14] Forman-Alberti, E.B. and Benjamin-Hinnant, J. (2016) Links between Autonomic Activity and Implicit Learning. International Journal of Psychophysiology, 110, 75-80. https://doi.org/10.1016/j.ijpsycho.2016.10.014

[15] Ohyama, T., Kaga, Y., Goto, Y., Aoyagi, K., Ishii, S., Kanemura, H., Aihara, M., et al. (2016) Developmental Changes in Autonomic Emotional Response during an Executive Functional Task: A Pupillometric Study during Wisconsin Card Sorting Test. Brain \& Development, 39, 187-195. https://doi.org/10.1016/j.braindev.2016.10.002

[16] Sanchis, L., Prat, P. and Sitges, M. (2016) Imagen cardiovascular en la sala de electrofisiología. Revista Española de Cardiología, 69, 595-605. https://doi.org/10.1016/j.recesp.2016.01.028

[17] Bermudez, E., Klerman, E., Czeisler, C., Cohen, D., Wyatt, J. and Phillips, A. (2016) Prediction of Vigilant Attention and Cognitive Performance Using Self-Reported Alertness, Circadian Phase, Hours since Awakening, and Accumulated Sleep Loss. PLoS ONE, 11, e0151770. https://doi.org/10.1371/journal.pone.0151770

[18] Graveline, I.M. and Wamsley, E.J. (2017) The Impact of Sleep on Novel Concept Learning. Neurobiology of Learning and Memory, 141, 19-26. https://doi.org/10.1016/j.nlm.2017.03.008

[19] Itzek-Greulich, H., Randler, C. and Vollmer, C. (2016) The Interaction of Chronotype and Time of Day in a Science Course: Adolescent Evening Types Learn More and Are More Motivated in the Afternoon. Learning and Individual Differences, 51, 189-198. https://doi.org/10.1016/j.lindif.2016.09.013

[20] Luque-Casado, A., Perales, J., Cárdenas, D. and Sanabria, D. (2016) Heart Rate Variability and Cognitive Processing: The Autonomic Response to Task Demands. Biological Psychology, 113, 83-90. https://doi.org/10.1016/j.biopsycho.2015.11.013

[21] Zhang and Cicoira (2018) Flexible Self-Powered Biosensors. Nature, 561, 466-467. https://doi.org/10.1038/d41586-018-06788-1

[22] Nathan, A., Ahnood, A., Cole, M., Lee, M., Suzuki, Y., Hiralal, P., Milne, W., et al. (2012) Flexible Electronics: The Next Ubiquitous Platform. Proceedings of the IEEE, 100, 1486-1517. https://doi.org/10.1109/JPROC.2012.2190168

[23] González-Barajas, J.E. (2014) Cálculo del umbral para detección de la onda R del complejo cardiaco. Tecno Lógicas, 17, 47-55. https://doi.org/10.22430/22565337.198 http://www.scielo.org.co/pdf/teclo/v17n32/v17n32a05.pdf

[24] Javier, G., Davis, M., Cristian, V. and Johann, N. (2015) R-Wave Detection Algorithm Using Integration of Virtual Instruments. 20th Symposium on Signal Processing, Images and Computer Vision, Bogota, 1-6. https://doi.org/10.1109/STSIVA.2015.7330434 
[25] Urbano (2017) Diseño de algoritmo para cuantificación de frecuencia cardiaca promedio en dispositivo ARM (máquinas avanzadas tipo RISC) Universidad Santo Tomás: Bogotá.

[26] Weippert, M., Kumar, M., Kreuzfeld, S., et al. (2010) Comparison of Three Mobile Devices for Measuring R-R Intervals and Heart Rate Variability: Polar S810i, Suunto t6 and an Ambulatory ECG System. European Journal of Applied Physiology, 109, 779-786. https://doi.org/10.1007/s00421-010-1415-9

[27] Geddes, M. (2017) Manual de Projetos do Arduinos. Novatec, São Paulo.

[28] MacRoberts, M. (2015) Arduino Básico. 2th Edition, Novatec, São Paulo.

[29] Monk, S. (2013) Programação com Arduino. Bookman, Porto Alegre.

[30] Monk, S. (2014) 30 projetos com Arduino. Bookman, Porto Alegre. 


\section{Appendix}

\section{Code on the ARDUINO Platform of the Attention Detection System Based on HRV}

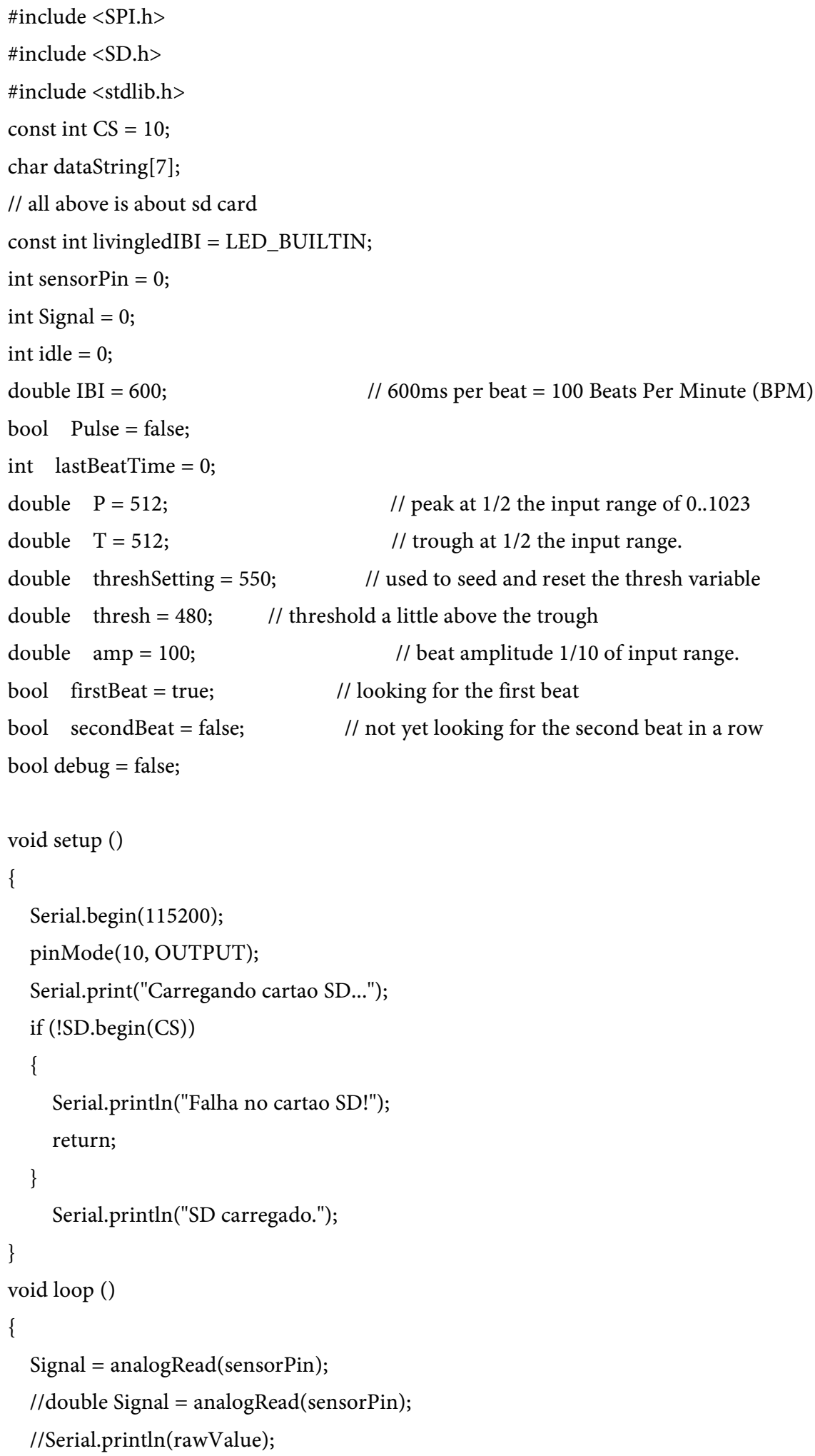


int now $=$ millis ()

int $\mathrm{N}=$ now - lastBeatTime; $\quad$ // monitor the time since the last beat to avoid noise

// find the peak and trough of the pulse wave

if $($ Signal $<$ thresh $\& \& N>($ IBI / 5) * 3$)\{/ /$ avoid dichrotic noise by waiting $3 / 5$ of last IBI

$$
\begin{gathered}
\text { if }(\text { Signal }<\mathrm{T})\{ \\
\mathrm{T}=\text { Signal; }
\end{gathered}
$$

$/ / \mathrm{T}$ is the trough

// keep track of lowest point in pulse

wave

\}

$$
\begin{aligned}
& \text { if }(\text { Signal }>\text { thresh \&\& Signal }>\mathrm{P})\{\quad \text { // thresh condition helps avoid noise } \\
& \begin{array}{l}
\mathrm{P}=\text { Signal; } \\
\text { \} }
\end{array}
\end{aligned}
$$

pulse wave

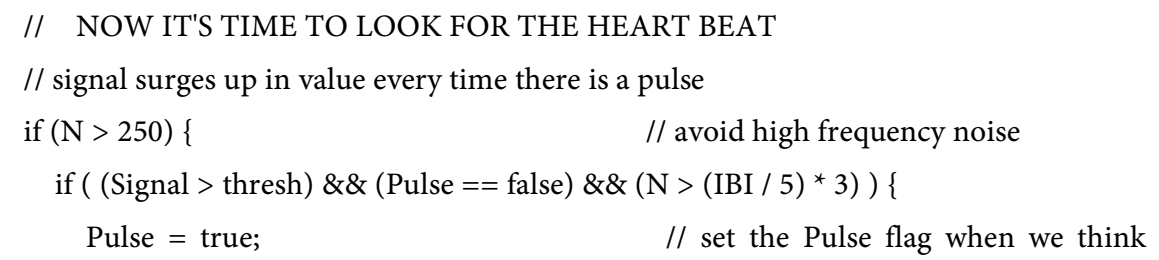
there is a pulse
IBI = now - lastBeatTime; $\quad$ // measure time between beats in $\mathrm{mS}$
lastBeatTime $=$ now;
// keep track of time for next pulse

idle $=0$;

if(!debug)\{

dtostrf(IBI,5,2,dataString); //sets IBI to sd

File pulsoIsaac $=$ SD.open("pulso.txt", FILE_WRITE); //open pulso.txt

pulsoIsaac.println(dataString); // write IBI to sd

pulsoIsaac.close(); // closes pulso.txt and save data

//Serial.print(IBI);

//Serial.print(",");

Serial.println(dataString);

\}

if (secondBeat) $\{\quad$ // if this is the second beat, if second-

Beat $==$ TRUE 


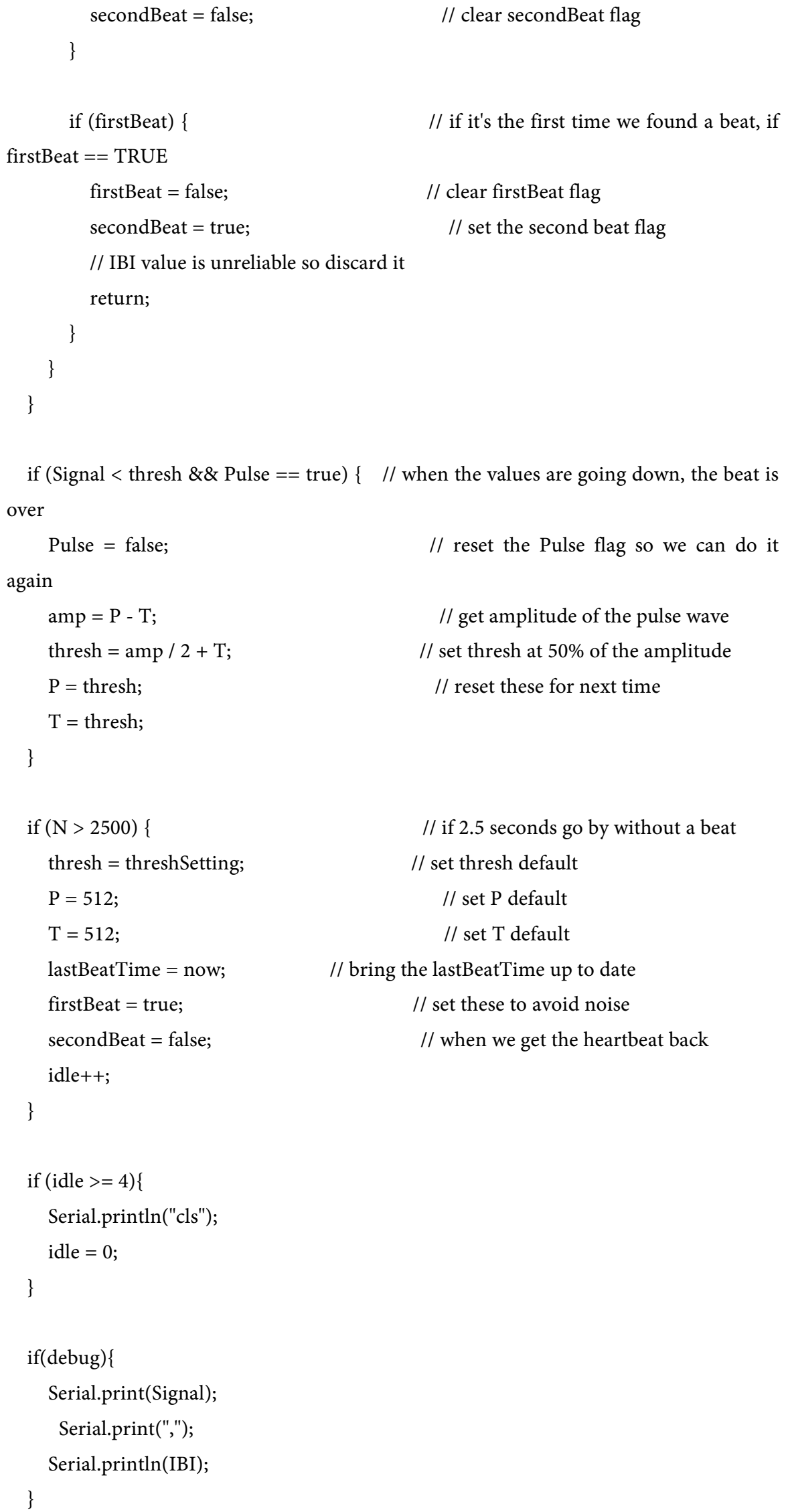

// get amplitude of the pulse wave $/ /$ set thresh at $50 \%$ of the amplitude // reset these for next time // set thresh default

$$
\text { // set } \mathrm{P} \text { default }
$$$$
\text { // set } \mathrm{T} \text { default }
$$

// bring the lastBeatTime up to date // set these to avoid noise // when we get the heartbeat back 


$$
\text { if(Signal > thresh })\{
$$

"turn-on" Arduino's LED. digitalWrite(livingledIBI,HIGH);

\} else \{

digitalWrite(livingledIBI,LOW); low "550", so "turn-off" this LED. delay (20);

\}
// If the signal is above "550", then

\section{Attention Detection System Based on HRV}

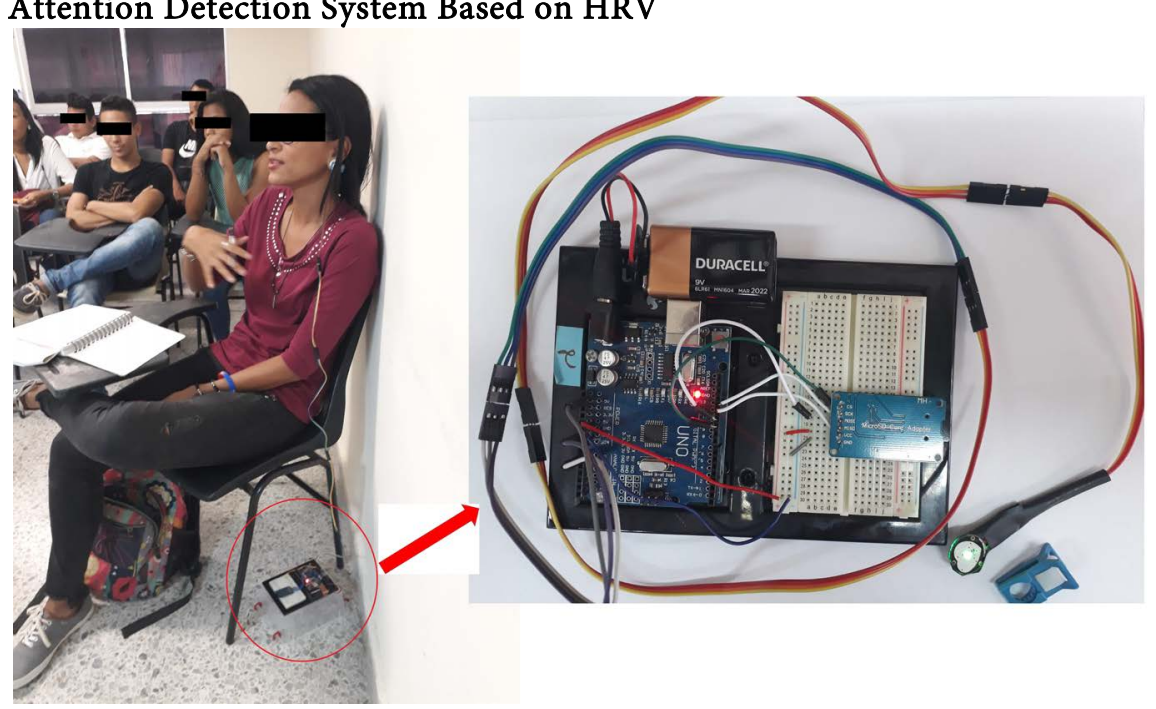

